actual rupture, and that rupture may occur with only weak contractions. (5) That the prognosis depends upon the time elapsing between rupture and laparotomy.

Early diagnosis of impending rupture should reduce the mortality to a minimum. In the case reported only a few minutes elapsed between rupture and the delivery of the child. A little earlier and the uterus might have been saved; a little later and two lives might have been lost.

I wish to thank Mr. Eardley Holland for his valuable criticism and suggestions, and for his permission to publish this case.

\section{MEIGS'S SYNDROME}

\section{HYDROTHORAX AND ASCITES IN ASSOCIATION WITH FIBROMA OF THE OVARY \\ BY}

AUSTIN C. CLAY, M.D.Aberd.

Senior Resident Physician, Aberdeen City Hospital

\author{
ROBERT N. JOHNSTON, M.B., Ch.B.Aberd. \\ Resident Medical Officer, Aberdeen City Hospital \\ AND
}

LEOPOLD SAMSON, M.D.Hamburg

Gynaecological Registrar, Aberdeen Royal Infirmary

Pleural effusion and ascites may be found in association with cardiac, renal, or hepatic disease, and in the absence of any such clearly defined clinical syndrome are commonly attributed to carcinomatosis or tuberculosis. The association of simple fibroma of the ovary with ascites is well known, free fluid sufficient to be recognizable clinically being found in $75 \%$ of cases. Pleural effusion in association with ascites and fibroma of the ovary is a rare condition. Only 28 cases have been reported in the literature, 27 of these being from America and one from Great Britain. It is our purpose to describe two such cases which have recently occurred in Aberdeen, as we believe that others may go unrecognized and, since ascites and hydrothorax immediately suggest an inoperable growth, some patients may have died unnecessarily. This is suggested by the fact that patients who were very seriously ill have made excellent recoveries after operation.

\section{Previous Cases}

The first case was reported by Cullingworth in 1879, and the patient died without operation. The condition was first described in 1892 by Lawson Tait, who advocated exploring the abdomen in patients with abdominal and chest fluid, for he considered that this combination did not always mean cancer. There was no further reference until 1923, when Hoon of the Mayo Clinic reported two cases. Meigs (1934) referred to 3 cases, reported 4 in collaboration with Cass in 1937, and in 1939 summarized 15 more cases. Later, in 1940, this total was increased to 18, while in 1943 further cases were described by Meigs et al., bringing the total of authentic cases described in America to 27. Rhoads and Terrell first used the term "Meigs' syndrome " when reporting a case in 1937. In Dec., 1943, Gild described one case in England.

\section{Recorded Signs and Symptoms}

In the majority of cases the history was that of dyspnoea, loss in weight, fatigue, cough, and pain in the chest, while on physical examination a massive pleural effusion was found in association with a greater or less quantity of abdominal fluid together with a pelvic tumour. The tumour may be a large and easily palpable mass associated with a clinically undetectable quantity of abdominal fluid or, alternatively, may be no larger than a walnut, only discoverable, in the presence of considerable ascites, at operation. In all cases the pleural effusion has been of a massive nature causing collapse of the lung on the affected side and displacement of the mediastinum. The condition may occur at any age, the oldest patient being 73 , and it has even been found complicating pregnancy. The right side of the chest is more often and usually more extensively affected than the left. There is no recurrence of the effusions after removal of the tumour, and indeed spontaneous resolution of the chest occurs within a few weeks. This is in marked contrast to what happens before operation, when, following the removal of large quantities of fluid, the chest fills up again in a matter of a few days, or in some cases within 24 hours. In some instances there is so little fluid in the abdominal cavity that paracentesis may fail to locate it, but some will always be found at operation.

\section{Case Histories}

Case 1.-An unmarried woman aged 59 was admitted to the gynaecological ward of the. Aberdeen Royal Infirmary with a complaint of breathlessness for the past year. She had noticed a lump in her abdomen for about the same period. The last menstrual period occurred ten years previously. The patient was emaciated and slightly orthopnoeic. There was a right pleural effusion, producing a mediastinal shift to the left. The abdomen was distended by a large irregular cystic swelling arising from the pelvis and reaching above the umbilicus. Vaginal examination revealed a small uterus distinct from the tumour. $X$-ray examination disclosed a large chronic effusion almost completely filling the right chest. The sputum showed no evidence of tubercle bacilli. The blood sedimentation rate was $15 \mathrm{~mm}$. in the first hour. Almost five pints of straw-coloured fluid was removed from the right pleural cavity. Bacteriological and pathological examination of this fluid failed to show evidence either of tuberculosis or of malignant disease. Laparotomy by Prof. Baird two weeks after admission demonstrated a big unilocular cyst about 8 in. in diameter attached to the left broad ligament. There was a small quantity of fluid in the peritoneal cavity. The cyst was removed and the abdomen closed. Histologically the tumour was shown to be a cellular ovarian fibroma with marked cystic degeneration but no evidence of malignancy. Recovery was rapid and no further breathlessness has been noted. Her general condition improved steadily and the emaciation quickly disappeared. A radiograph of the chest three months after operation showed the lungs to be normal.

Case 2.-A married woman aged 47 who had one child, now aged 25, was admitted to Aberdeen City Hospital as a case of pulmonary tuberculosis. Her complaint was breathlessness for the past five months. The menstrual history was normal. She was a thin, rather wasted woman-breathless while lying in bed. There was a large pleural effusion on the right side with a slight mediastinal shift, and on abdominal palpation a large mass was felt rising out of the pelvis to the level of the umbilicus, but no free fluid could be detected. On vaginal examination a hard mass was very easily felt in the right fornix. $X$-ray examination of the chest showed a large pleural effusion on the right side. The left lung was normal. No tubercle bacilli were found in the sputum by direct film or on animal inoculation. The blood sedimentation rate was $10 \mathrm{~mm}$. in the first hour. The right pleural cavity was aspirated and the fluid replaced by air. The fluid was clear, and histological examination of centrifuged deposit showed no evidence of malignant disease, while animal inoculation of two specimens failed to reveal the presence of tubercle bacilli. Subsequent $x$-ray examination disclosed a right hydropneumothorax with complete collapse of the right lung. In all, 35 pints of fluid were removed from the right pleural cavity. Paracentesis of the abdomen failed to elicit fluid. An exploratory laparotomy was performed by Prof. Baird two months after admission. There was less than a pint of fluid in the peritoneal cavity, and a large white lobulated tumour ( 7 by 6 in.) was found attached by a pedicle to the right broad ligament posteriorly. The left ovary was normal. The tumour was removed, and proved to be a typical ovarian fibroma with no evidence of malignancy. Post-operative convalescence was uneventful. Further radiographs of the chest showed rapid absorption of the right pleural effusion, and ten weeks after operation only a trace of fluid was detectable. The right lung had expanded, and the patient's general condition had greatly improved.

\section{Aetiology}

No satisfactory explanation exists to account for the phenomenon. The suggestions which have been offered are: (1) lack of drainage of the right chest by the azygos vein ; (2) repeated minor trauma to the peritoneum by the fibroma, causing a histamine toxicosis or anaphylactic shock plus accumulations of peritoneal and pleural transudate; (3) congenital communication between the abdomen and the chestthe so-called pleuro-peritoneal canal.

None of these explanations have been satisfactorily proved. Meigs $e t$ al. introduced a quantity of air into the pleural cavity, the patient then being tilted into the Trendelenburg position and $x$-rayed without any evidence of air being forced into the abdomen. The reverse procedure, whereby a considerable quantity of air was pumped into the abdomen to the point of discomfort and dyspnoea in an effort to demonstrate any passage-way for air from the abdomen to the thorax, has also 
failed. In two patients $2 \mathrm{c.cm}$. of sterile Indian ink was injected into the abdomen, and chest taps were performed later. In each case the fluid in the chest showed the same concentration of Indian ink as that in the abdomen. That the Indian ink did not arrive in the pleural fluid by way of the blood stream was considered established by study of the blood, since no evidence of Indian ink could be found in the leucocytes on microscopical examination. This experiment suggested that the abdominal fluid may arrive in the chest by the same paths as the Indian ink, or vice versa. The probability is that the pathways are lymphatics which pass through the interstices of the serosal cells under the diaphragm, thence to the supradiaphragmatic lymphatics and so into the chest.

\section{Summary}

Two cases of Meigs's syndrome (fibroma of the ovary with pleural effusion and ascites) are.described.

This condition is probably rare, but without doubt some cases go unrecognized, since they are often ill and simulate advanced carcinoma of the ovary or severe cardiac, renal, pulmonary, or hepatic disease. This is most unfortunate, since such patients' would be denied an operation which gives excellent results.

The syndrome must always be considered in a differential diagnosis of abdominal and chest effusions, and as only one other case has been described in the British literature in the last 20 years we feel that the occurrence of two cases within a year among a relatively small population suggests that some cases are being overlooked.

We wish to thank Prof. Dugald Baird and Dr. John Smith for their interest and encouragement.

\section{REFERENCES}

Cullingworth, C. J. (1879). Trans. obstet. Soc., London, 21, 276

Gild, Albert (1943). J. Obstet. Gynaec. Brit. Emp., 50, 440.

Hoon, M. R. (1923). Surg. Gynec. Obstet., 36, 247.

Yigs, J. (1934). Tumours of the Female Pelvic Organs, Macmillan, New York.

(1939). Ann. Surg., 110, 731.

1940). Frank Howard Lahey Birthday Volume, p. 331

Armstrong, S. H., and Hamilton, H. H. (1943). Amer. J. Obstet. Gynec., 46. 19.

Rhass, J. W. (1937). Itid., 33, 249

Ass, 109, 1684

Rho

\section{Medical Memoranda}

\section{Fibrositis of the Rectus Abdominis Muscles causing Dyspepsia}

Numeicus cases of dyspepsia, or pain after food, fail to reveal any physical abnormality on ordinary routine examination. Even $x$-ray investigation of the stomach, duodenum, and gall-bladder is equally sterile of definite evidence of disease, and vague diagnoses of gastritis, duodenitis, or chronic cholecystitis are made. The patient continues to complain of indefinite pain - sometimes soon, sometimes late after food. He undergoes long courses of careful diet and takes much alkaline powder. Finally he or she drifts into a hypochondriac state, having given up all the joys of life which are associated with eating, drinking, and smoking.

In treating such cases one will be well repaid by making a careful examination for tender areas of fibrositis in the upper ends of the rectus abdominis muscles-particularly in their origins from the surfaces of the fifth to the seventh costal cartilages, the xiphoid cartilage, and the costo-xiphoid ligament. In a surprising number of cases tender nodules of fibrositis will be found, and after these have been "broken up" and treated by skilful massage the dyspeptic symptoms will disappear as if by magic and the patient will regain robust health

I have had some difficulty in getting masseuses to carry out the treatment properly. The massage should be done with the tips of the fingers, working the skin in a circular movement and pressing upon the tender area as deeply and firmly as the patient will allow-short of bruising the tissues. Light stroking movements have as little curative effect as sticking on a tenand-sixpenny stamp, the usual fee for the attendance. Masseurs should have three main qualifications - very sensitive fingers, very strong fingers, and complete ruthlessness! Massage should be given twice or, at the most, three times a week; there is always a certain amount of reaction and general tenderness after "breaking up" the fibrositic nodules, and this must be allowed to settle down before the next treatment is given. But, by starting with light pressure and gradually increasing it, a skilful masseur will soon take out the tenderness. An infra- red lamp will help considerably, but it should be left with the patient to use for hours at a time.

The rectus abdominis muscle is supplied by branches from the fifth to the twelfth thoracic segments. These same segments also send branches to the coeliac plexus. Fibrositis may cause a reflex action in the abdominal organs, giving rise to spasm or dysfunction.

\section{Illustrative Cases}

Case 1.-Mr. A., aged 52, was well till five years ago, then began to have indigestion. The pain had no time relation to food, but was sometimes relieved by it. $X$-ray examination showed an active and normal duodenum and gall-bladder. His sinuses were radiographed and found to be normal; likewise his spine. For a month , he was "investigated" in the private ward of a large hospital, but he was " investigated" in the private ward of a large hospital, but from the rest. One physician told him he was suffering from aortitis, but a second negatived this by means of a cardiogram. When I first saw him he looked ill and debilitated. He felt sick and had pain after every meal, but seldom vomited. When he could vomit pain after every meal, but seldom vomited. When he could vomit he felt relief. He was living on a special diet of milk, fish, and
breast of chicken. I asked him to put his finger on the spot where he felt pain, and to my surprise he indicated the right costal margin, where I found a patch of acutely tender fibrositis, which he would hardly allow me to touch. I massaged this, and he felt better that same day. I got a good masseuse to treat him with massage and an infra-red lamp, and in three weeks he was a perfectly well man, taking full meals with beer, and sleeping well and putting on weight. He also smoked and took cocktails with no bad results. The only medicine I gave him was 15 minims of dilute hydrochloric acid with meals, and this he discarded after two weeks.

Case 2.-Mr. B., aged 44, told me he had had a duodenal ulcer for the past 17 years. His gall-bladder was removed nine years ago after $x$ rays had shown the ulcer to be healed. But three years later he had severe haematemesis, and the ulcer became active again. Since then many radiographs had shown the ulcer to be healed, but he still complained of violent pains after food, particularly at night. He had much business worry. On examination I found marked tender fibrositis in the upper ends of both rectus abdominis muscles. No medicine was given, and a course of massage and infra-red treatment cured his "indigestion,"

Case 3.-Mr. C., aged 68. His was an old duodenal case with a history of melaena on two occasions. Recent bismuth meal examinations revealed a healed posterior duodenal ulcer. Nine months ago he began to suffer acute pain in the upper abdomen, which had no relation to food, but which was always worse at night and even woke him up most nights. He had tender fibrositis in the origin of the right rectus muscle. I massaged this, and next day he teleof the right rectus muscle. I massaged this, and next day he tele-
phoned from his home 50 miles away that he had slept all night without pain for the first time in nine months. He has had a course of massage, and has not had any trace of pain since.

London, S.W.7.

$$
\text { R. Simpson HarveY, M.B., B.S.Lond. }
$$

\section{Diaphragmatic Hernia with Torsion of the Stomach and Acute Obstruction}

The case described below came under my care, and the operation revealed such unusual conditions that it seems worth recording.

\section{CASE RECORD}

Mrs. X., aged 57, was admitted on April 2, 1943, to an emergency hospital with symptoms of acute pain in the chest and distension of the upper part of the abdomen. There was a history of a diaphragmatic hernia, diagnosed and confirmed by $x$-ray examination at the King Edward VII Hospital, Windsor, in 1939. The symptoms at that time were of epigastric discomfort relieved by belching. This continued at varying intervals, and she was admitted to the same hospital in September, 1941, when she was also found to have a left inguinal hernia. A radical cure was performed on this, and the patient made an uneventful recovery, being discharged on Oct. 11. The attacks of discomfort in the upper abdomen continued at irregular intervals, and on April 2,1943, she was seized with acute pain in the left side of the chest. This was accompanied by ineffectual attempts at vomiting. She was admitted the same evening to the emergency hospital, and on examination was found to be greatly distended in the epigastrium, the rest of the abdomen being flat. The appearance was very striking, and was clearly due to a greatly distended stomach. Her pulse was low (64), and temperature subnormal $\left(96.6^{\circ}\right)$. There were sounds of borborygmi to be heard in the left side of the chest.

An operation was performed without delay through a left paramedian incision. The stomach at once presented itself, very tense and like a distended rubber balloon. By passing the hand round the left-hand surface of the stomach it was possible to reach the edge of the diaphragmatic aperture, and by manipulation the intraedge of the diaphragme stomach was successfully withdrawn. The thoracic portion of the stomach was successfully withdrawn. The moment this was done the whole stomach turned over from right to
left. In its distended condition it was approximately 18 to 20 in. long and 8 or 9 in. in diameter. It was clear that there was then no obstruction at the pylorus. By turning the stomach over to the right it was possible to see the opening in the diaphragm, which was to the left of the oesophageal opening, and admitted two fingers easily. The opening was occluded by a stout double catgut suture, and the abdomen was closed. On April 5 there were signs of a left-sided basal pneumonia, which cleared up in a few days, and the patient was discharged on April 19 with no symptoms. 